\section{Commentary: Microvesicles: A target for personalized medicine following coronary artery bypass grafting}

\author{
Nicolas H. Pope, MD, ${ }^{a}$ and Arman Kilic, $\mathrm{MD}^{\mathrm{b}}$
}

Graft patency after coronary artery bypass grafting (CABG) is clinically important, as graft occlusion is associated with increased need for repeat revascularization and mortality. ${ }^{1}$ The natural history of all bypass grafts is one of failure over time, the rate of which may be affected by a multitude of factors. Although early graft failure is thought to be largely related to technical issues, medium- and long-term graft patency are thought to be affected by multiple risk factors, including patient-related factors such as continued smoking and poorly controlled diabetes, conduit type (arterial vs venous), graft type (in situ vs free), and more difficult-to-quantify factors, such as competitive flow and distal runoff. ${ }^{2-4}$

In this issue of the Journal, Moore and Harken ${ }^{5}$ review the work of Camera and colleagues, ${ }^{6}$ who retrospectively examined the influence of preoperative patient microvesicles as a predictive marker for graft failure at 18 months after CABG. As Moore and Harken point out, higher preoperative levels of inflammatory and platelet derived microvesicles were associated with higher rates of both arterial and saphenous vein graft thrombosis, suggesting a patient specific (and potentially intervenable) cause for mid-term graft thrombosis. Interestingly, this association was independent of conduit type.

From the ${ }^{\mathrm{a} D i v i s i o n}$ of Cardiothoracic Surgery, Medical University of South Carolina, Charleston, SC; and ${ }^{\mathrm{b}}$ Division of Cardiac Surgery, The University of Pittsburgh Medical Center, Pittsburgh, Pa.

Disclosures: Dr Kilic serves on the Medical Advisory Board for Medtronic. Dr Pope reported no conflicts of interest.

The Journal policy requires editors and reviewers to disclose conflicts of interest and to decline handling or reviewing manuscripts for which they may have a conflict of interest. The editors and reviewers of this article have no conflicts of interest.

Received for publication Nov 3, 2020; revisions received Nov 3, 2020; accepted for publication Nov 4, 2020; available ahead of print Nov 19, 2020.

Address for reprints: Arman Kilic, MD, University of Pittsburgh Medical Center, 200 Lothrop St, Suite C-700, Pittsburgh, PA 15213 (E-mail: kilica2@upmc.edu).

J Thorac Cardiovasc Surg 2022;163:700-1

$0022-5223 / \$ 36.00$

Copyright $\Subset 2020$ Published by Elsevier Inc. on behalf of The American Association for Thoracic Surgery

https://doi.org/10.1016/j.jtcvs.2020.11.021
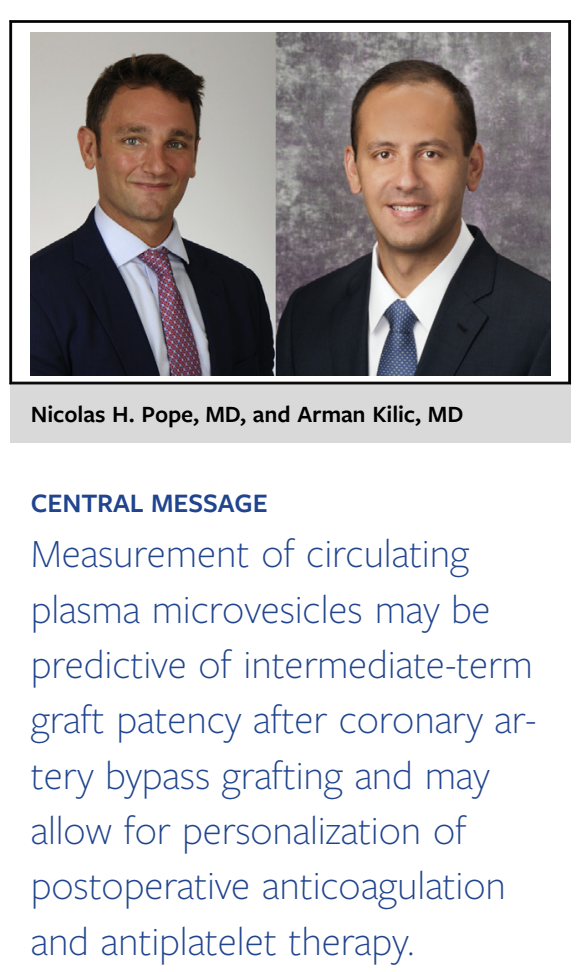

Although previous studies have attempted to associate genetic and cellular predictors of graft failure after CABG, these studies have focused on the progression of atherosclerosis as a cause for graft failure, thus limiting the ability to intervene beyond the current recommendation for lipid-lowering therapy already considered best practice after CABG. ${ }^{7,8}$ As the authors point out, a personalized, preoperative risk assessment for graft thrombosis may allow for tailoring of postoperative antiplatelet or anticoagulant therapy in an attempt to maintain graft patency.

Further investigation in attempts to reduce graft thrombosis in patients with high microvesicle scores is clearly needed. The benefit of dual prolonged antiplatelet or anticoagulant therapy in these patients remains controversial. Moreover, no commercially available measurement of inflammatory or platelet-derived microvesicles is available; however, should a benefit be demonstrated, a commercially available "microvesicle risk score" may become an important part of clinical practice, much in the same way that oncologic gene profiles have changed the care of cancer patients and allowed for personalized and individually tailored treatment.

\section{References}

1. Fitzgibbon GM, Kafka HP, Leach AJ, Keon WJ, Hooper GD, Burton JR. Coronary bypass graft fate and patient outcome: angiographic follow-up of 5,065 grafts 
related to survival and reoperation in 1,388 patients during 25 years. $J$ Am Coll Cardiol. 1996:28:616-26.

2. Collins P, Webb CM, Chong CF, Moat NE, Radial Artery versus Saphenous Vein Patency (RSVP) Trial Iinvestigators. Radial artery versus saphenous vein patency randomized trial: five-year angiographic follow-up. Circulation. 2008;117: 2859-64.

3. Kim KB, Cho KR, Chang WI, Lim C, Ham BM, Kim YL. Bilateral skeletonized internal thoracic artery graftings in off-pump coronary artery bypass: early result of Y versus in situ grafts. Ann Thorac Surg. 2002;74: S1371-6.

4. Sabik JF III, Blackstone EH. Coronary artery bypass graft patency and competitive flow. J Am Coll Cardiol. 2008;51:126-8.
5. Moore H, Harken A. Managing microvesicles or Virchow's vicissitude. J Thorac Cardiovasc Surg. 2022;163:696-7.

6. Camera M, Brambilla M, Canzano P, Cavallotti L, Parolari A, Tedesco CC, et al Association of microvesicles with graft patency in patients undergoing $\mathrm{CABG}$ surgery. J Am Coll Cardiol. 2020;75:2819-32.

7. Grinshtein YI, Kosinova AA, Grinshtein IY, Subbotina TN, Savchenko AA. The prognostic value of combinations of genetic polymorphisms in the $\mathrm{ITGB}_{3}$, ITGA $A_{2}$, and $\mathrm{CYP}_{2} \mathrm{C} 19 * 2$ genes in predicting cardiovascular outcomes after coronary bypass grafting. Genet Test Mol Biomarkers. 2018;22:259-65.

8. Taşoğlu I, Turak O, Nazli Y, Ozcan F, Colak N, Sahin S, et al. Preoperative neutrophil-lymphocyte ratio and saphenous vein graft patency after coronary artery bypass grafting. Clin Appl Thromb Hemost. 2014;20:819-24.
See Article page 696.

\section{Commentary: Microvesicles, personalized surgery, and tailored medical therapy to improve coronary artery bypass grafting outcomes}

\author{
Derrick Y. Tam, MD, PhD, and \\ Stephen E. Fremes, MD, MSc
}

When it comes to graft patency in coronary artery bypass grafting (CABG), there are likely myriad factors, such as patient baseline characteristics, coronary anatomy, and procedure-related aspects, that are associated with outcomes. ${ }^{1,2}$ It is up to a surgeon to weigh all these different considerations when it comes to deciding what operation to offer his or her patient. In coronary surgery, the key procedure-related questions include off-pump or on-pump, multiple arterial grafts versus supplemental vein grafts, conduit harvesting techniques (eg, skeletonization, no touch,

\footnotetext{
From the Division of Cardiac Surgery, Schulich Heart Centre, and Department of Surgery, Sunnybrook Health Sciences Centre, University of Toronto, Toronto, Ontario, Canada.

Disclosures: The authors reported no conflicts of interest.

The Journal policy requires editors and reviewers to disclose conflicts of interest and to decline handling or reviewing manuscripts for which they may have a conflict of interest. The editors and reviewers of this article have no conflicts of interest.

Received for publication Nov 26, 2020; revisions received Nov 26, 2020; accepted for publication Nov 30, 2020; available ahead of print Dec 4, 2020.

Address for reprints: Stephen E. Fremes, MSc, MD, FRCSC, FACP, FACC, Department of Surgery, Sunnybrook Health Sciences Centre, 2075 Bayview Ave, Room H4 05, Toronto, Ontario M4N 3M5 Canada (E-mail: Stephen.fremes@ sunnybrook.ca).

J Thorac Cardiovasc Surg 2022;163:701-2

$0022-5223 / \$ 36.00$

Copyright (C) 2020 by The American Association for Thoracic Surgery

https://doi.org/10.1016/j.jtcvs.2020.11.142
}

Check for updates

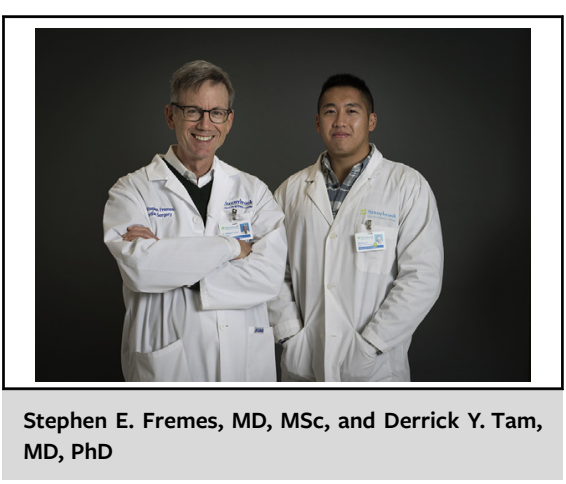

CENTRAL MESSAGE

Future advancement in under-

standing microvesicle signature

can help to tailor both surgical

and medical therapy in patients

undergoing coronary artery

bypass grafting.

or endoscopic), and which conduits should be anastomosed to which diseased vessels. ${ }^{3-5}$ These considerations are carefully weighed based on the patient's baseline level of health, comorbidities, conduit quality and availability, and the anatomy of the diseased coronary vessels. Moore and Harken ${ }^{6}$ review an article that looked at microvesicles; that is, circulating molecules in the blood that when analyzed, provide a unique signature to describe an individual's coagulation profile (eg, whether he or she in a prothrombotic state or not). Moore and Harken ${ }^{6}$ argue that perhaps surgeons have been too hard on themselves when it comes to graft failure and that some of the blame can instead be explained by a hypercoagulable profile. As Moore and Harken ${ }^{6}$ point out, 